\title{
JOAQUIM MANUEL MAGALHÃES: O EROS SEM MÁSCARAS
}

Míriam Soares Silva Universidade do Estado de Minas Gerais - Divinópolis

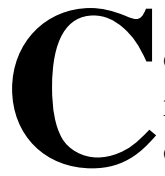

onsiderado o mentor intelectual dos poetas contemporâneos portugueses (pós 70), Joaquim Manuel Magalhães destaca-se como poeta e crítico. Compõe num estilo próprio, mas trazendo as marcas da poesia de Cartucho - obra coletiva que assume uma atitude intencional de contestação, pois tem a particularidade de não se apresentar sob a forma de livro: é um cartucho onde os poemas dos seus quatro poetas se apresentam amarrotados.

Dentre os traços principais dessa poesia, o mais marcante, e que encontraremos inclusive na poética de Joaquim Manuel Magalhães, será, como ele próprio diz: "um ímpeto renovado de se contar, de assumir, por máscara ou directamente, um discurso cuja tensão é menos verbal do que explicitamente emocional." Representa-se na escrita pela narratividade, pela subjetividade, através do lirismo assumido, numa tendência clara do retorno da presença do sujeito ao texto, o que, conforme afirma o crítico Fernando Pinto do Amaral, "nos dá a ilusão de um discurso mais sentido." É a poesia da experiência, da reaproximação do real, que recai num microrealismo, no gosto pelo detalhe. E a representação do exercício da sexualidade homoerótica também constitui um traço importante dessa poesia.

Abrimos um parêntese para lembrar a importância da temática homossexual para a jovem poesia portuguesa. Como escreve Eduardo Prado Coelho, "...a homossexualidade é uma das áreas

${ }^{1}$ MAGALHÃES, 1981. p.258. 
temáticas mais intensas e explícitas da poesia portuguesa contemporânea..."; ${ }^{2}$ teria passado de tabu a realidade culturalmente produtiva. Segundo Fernando Pinto do Amaral, deve-se a Joaquim Manuel o pioneirismo na literatura portuguesa de "assumir sem reservas a sensibilidade homossexual, não hesitando em explicitar o gênero gramatical da pessoa amada." "3 Nos seus poemas a opção erótica é revelada de maneira visível, principalmente em Antônio Palolo, um dos vários livros compilados em Alguns livros reunidos ${ }^{4}$ e que constituirá o corpus desse trabalho. Trata-se de quinze poemas numerados, sendo que apenas três têm título. Assim, analisar o homoerotismo na poética de Joaquim Manuel será nosso principal objetivo; além de verificar os traços da poesia de Cartucho presentes em seu texto, bem como apontar alguns símbolos recorrentes e outras marcas de seu estilo. Para tanto, iremos nos valer principalmente da teoria psicanalítica, no que esta se refere às questões do homoerotismo. Vale esclarecer que o título inusitado, Antônio Palolo, é uma homenagem do poeta ao pintor de mesmo nome, seu amigo.

Nas primeiras leituras dos poemas do poeta português observamos uns ecos de romantismo, no tom confessional do "eu poético", na temática recorrente da tristeza, da melancolia, da dor de amor, da desventura amorosa, da saudade, da busca do passado. Nossa percepção pôde ser confirmada pelas afirmações de Fernando Pinto do Amaral:

Mas talvez o traço mais sensível da metamorfose pós 70 tenha a ver com os sentimentos, que pouco a pouco foram retomando alguns direitos, perdidos sobretudo na época áurea de um certo estruturalismo ou de uma certa psicanálise, quando era quase um crime serse subjetivo (...) Sinais de um novo romantismo? À falta de outro nome, chamemo-lhes assim, mas tendo consciência de que a História, não sendo linear nem circular, progride talvez em espiral,

${ }^{2}$ COElHO, 1988. p.123.

3 AMARAL, 1991. p.102.

${ }^{4}$ MAGALHÃES, 1987. 
Ou

consciência de que a História, não sendo linear nem circular, progride talvez em espiral, ou por outras palavras; recuperada a noção de subjetividade, ela e agora uma subjetividade diferente menos centrada sobre cada sujeito ou, se quisermos, mais passiva e anônima, irremediavelmente dispersa e sem lugar. ${ }^{5}$

Acrescentaríamos que tais poetas, e em especial Joaquim Manuel Magalhães, não só cantam o amor "envolto pelas camadas da névoa da distância”, mas o amor homerótico, experimentado e assumido, diferenciando-os e muito dos poetas românticos que cantavam o amor platônico, irrealizado. Trata-se de um amor maldito, de conotação decadentista, marcado não só pela dor, mas pela culpa. O "eu poético" de Antônio Palolo, numa forma discursivo-narrativa nos revela as aventuras e mais ainda as desventuras do amor homoerótico, o drama dos desencontros, do amor fortuito e marginal, nos vãos de escadas, nas praças, nos jardins, nos metrôs, nos cais...

Em Joaquim Manuel Magalhães: o amor em trevas, Edgard Pereira, estudioso dos poetas de Cartucho, nos mostra como aparece o sentimento de culpa, o erotismo fluido, ambíguo, não assumido, nos primeiros livros do poeta, e que evoluiria para um homoerotismo assumido nos outros livros. Analisa ainda a correspondência entre o sentimento de culpa com as imagens tenebrosas. Mas, ao analisarmos os poemas de Antônio Palolo, constatamos que, ainda que assumida a atitude homoerótica, as relações reveladas aparecem marginalizadas, e o sentimento de culpa persiste, mesmo de forma velada, disfarçado pela tristeza, pela angústia; enfim, "o amor em trevas" de certa forma permanece. No entanto, o estudo citado nos orientou com várias pistas, como por exemplo, no que se refere ao diálogo estabelecido nos poemas, enquanto recuperação da urgência do diálogo, "através do qual refaz elementos intratextuais do diálogo platônico - entre o próprio eu e o outro, ou entre o eu e o mim." 6

\footnotetext{
5 AMARAL. In: A phala, 1989. p.162.

${ }^{6}$ PEREIRA, 1999. p.111-119.
} 
O apelo constante a uma segunda pessoa nos remete a um outro ambíguo. De um modo geral, o "tu” parece se dirigir ao outro enquanto o amado, o objeto da sedução homoerótica. Já no poema Sete o "eu poético" relembra o medo, a culpa na descoberta do amor proibido, da época em que "o amor fazia-me tão mal que mal amava”. Ao avaliar o passado, questiona a própria identidade, numa referência ao diálogo entre o "eu" e o "mim". Estabelece-se dessa forma a questão do fingimento, da máscara, da multiplicidade do "eu"; o que pode ser comprovado em "Sou eu, esta ilusão"; vejamos:

Começo onde a memória dói.

Os rostos dos outros o medo

nem sei. Digo isto. De tais coisas

foram feitos os meus dias

puros sons quebrados por sons puros.

Erros rasgões as alegrias

máscaras, nem é bem isso,

lutas, inimigas dores.

O terror da gramática leva-me

à segunda pessoa que ninguém sabe

quem és. Sou eu, esta ilusão

onde começa tudo.

A retomada da relação erótica prenunciada na pedagogia socrática encontra-se no poema Quatro: "O que te ensinei, tu tens razão,/estou a ensinar-te. Eu digo só a ti/o que não sei e não tem mal,/é tudo igual ao que te ensinei." Segue neste tom didático: "Por mais longe que um homem ande/ quem o amou anda com ele (...). Vê como vai o coração nestas verdades aprendido."

Estamos ainda de acordo com a visibilidade erótica apontada como flagrante no poema Três, de exemplaridade antológica nesse sentido. O poema inicia-se com a narração do assédio pelo "eu poético" a um empregado do supermercado que freqüenta: "Comprei-lhe requeijão durante vários dias". É correspondido: "Rilhe o primeiro convite. Riu-se em trocos." Nota-se o trocadilho feito com "trocos", sugerindo tanto troco (moeda) como troca (sedução), ressaltando a preocupação formal do poeta, embora o poema seja marcado pela narratividade. O jogo da sedução se passa também 
pelo olhar: "a cada espaço vazio de caixotes/ o seu olhar a seguir as minhas compras." Na segunda estrofe a atitude homoerótica assumida explicita-se em: "Fui atrás soube-lhe as horas de sair / vim esperar depois da caixa, à porta."

Tudo isso é contado com tanta naturalidade e lirismo como no verso: "Os carros iam de regresso as casas / o ar toldado de novembro em sol", que o leitor certamente se sentirá envolvido, sem questionar a natureza erótica que motiva tais sentimentos. Já a terceira estrofe nos narra o encontro sexual em detalhes : "Chegou metendo um pente n'algibeira”, sugerindo o próprio ato sexual. E prossegue: "que eu fechava os olhos para perdurar/ até tirar-lhe a camisola, as meias / trocar o meu hálito de dentífricos / pelo seu cansado de ervas doutras formas." Ao final, a partida, a separação, a cruel realidade que acompanha a relação homoerótica de encontros casuais: "o corpo satisfeito mas fendido / do prazer combinado para outro dia / que podia voltar ou não a haver."

Realmente o poema acima não nos traz a carga de culpa nem as imagens tenebrosas de outros. É, como afirma Edgard Pereira, um exemplo de como a opção homoerótica se mostra visível, à luz dos supermercados. Mas o aspecto marginal que marca o homoerotismo como maldito, aparecerá em outros poemas do mesmo livro; carregado de tristeza, da melancolia, da relação homoerótica discriminada, de referências a espaços escusos, sórdidos. Enfim, não será um homoerotismo luminoso em oposição ao "amor em trevas". No poema Quatro, as imagens de tarde, cactos, vidros, pedra, neblina, sugerem a aridez da solidão, da separação, os obstáculos enfrentados no amor homoerótico; explicitado em "amar é separar". E sobre as mãos, metonímia do corpo, diz: "Vê como ardem e se vão embora/ para outra escolha. A rir-se, a bem dizer." Novamente nos faz lembrar as afirmações de Fernando Pinto do Amaral: "A distância de quem parte, de quem fica, de quem olha e saboreia com um perverso prazer a sua própria dor." 7

${ }^{7}$ AMARAL, In: A phala, 1989. p.162. 
O crítico associa este estado de alma à melancolia, à "mágoa como vício", tão cara a vários outros poetas portugueses. Caracteriza ainda a melancolia como sentimento pós-moderno, decorrente da dessacralização ou fragilização da arte, e que faz da escrita também um "vício", ou um hábito. Esse sentido da melancolia cabe perfeitamente na poética de Joaquim Manuel Magalhães; no entanto, optamos por analisá-la noutro sentido.

A propósito, podemos relembrar desde Hipócrates o primeiro sentido de "bile negra", humor negro, e Aristóteles que considerava o melancólico mais apto para as atividades do pensamento e das artes, desde que mantivesse um equilíbrio em relação aos outros humores. Mais ainda pertinente seria rever, numa perspectiva psicanalítica, algumas características do melancólico: a crise, o sentimento de perda do objeto amoroso e de que a salvação reside no outro, a tristeza como falta, carência vital; seriam todas possíveis de se associarem ao estado de alma que predomina no "eu poético" que nos fala nos poemas de Antônio Palolo, senão vejamos:

Tenho uma tristeza
no bolso de dentro
do velho casaco,
Dobrada, quebrado.
Tenho uma tristeza
suja de papel
e de letras gastas.
(...)
Charcos de jardim
dádiva na mão
triste, por abrir
e depois a dor
aperta-me o punho
por anoitecer
Venho duma rua
para o teu lugar.

No poema Onze lemos: "As roupas espalhadas no soalho / vesti-las, ir da nossa rua / tu e eu havemos de apanhá-las, / para as outras ruas, / regressar às melancolias e às aventuras." Ou : "Que vou 
fazer do corpo tão distante / das tuas mãos indo pelo corredor/ nos bolsos junto às tuas pernas?"

Vê-se a tristeza reiterada, a metáfora de "charco" para representar o vazio, o pântano da alma solitária, a angústia do desejo e perda do objeto amoroso; e a explicitação da busca da melancolia, numa referência bem romântica. A esse respeito Freud afirma: "O afeto correspondente à melancolia é o luto - ou seja, o desejo de recuperar algo que foi perdido. Assim na melancolia, deve-se tratar de uma perda na vida pulsional." 8 Vale lembrar que o sentido freudiano para melancolia corresponde ao que hoje chama-se de depressão.

No estudo A aquisição e o controle do fogo, Freud cita o mito de Prometeu - o portador do fogo, que o roubou dos deuses e o trouxe aos homens, sendo castigado a ficar acorrentado a um rochedo, tendo um abutre a comer-lhe o fígado (órgão considerado sede de todas as paixões e desejos). Freud faz a analogia do simbolismo do mito com a representação dos processos mentais. O fogo, símbolo da libido, é a paixão do amor erótico para o homem primitivo; mas a aquisição do "fogo", do desejo constitui crime; há a exigência de se renunciar ao instinto, de reprimi-lo. A ave que se alimenta do fígado teria a significação do falo a tocar a fonte do desejo, que é indestrutível e que revive depois de saciado.

Observamos que o sentido para vários símbolos da poética de Joaquim Manuel encontra consonância no mito prometeico. $\mathrm{O}$ fogo e a ave, a par de outros símbolos, como o sangue, o vento, o charco, são recorrentes. O fogo já foi citado como metáfora para a paixão avassaladora nos primeiros livros do poeta: "A chorar devagar o corpo vai/ pelo rápido sossego de campos / as trevas do amor acendem-se." Em Antônio Palolo aparece várias vezes, e, a nosso ver, ainda associado ao "amor em trevas":

${ }^{8}$ FREUD, 1987. p.247. 
Entra-se na praça por escadas de cimento

lixo entornado pelos cães.

Um riso triste pega no isqueiro.

Acende-o. Queima

o corpo na boca doutro corpo.

Por pequenas horas, por alguns escudos.

Vou-me embora. Vou sem ti. Este recanto

foi o último, parece uma ruína, os neons

combatem ao vento contra o céu de fogo.

Ou:

A boca sossega coberta do fogo

onde corre o esperma das lágrimas.

Estalam no ateado azinho

vão de vez pela fuligem fora...

No poema Dez: "O rançoso verde militar / traça entre nós dois muro/ cem chamas sem fogo que nos perdem"; no poema Doze: "Desse fundo, desse fogo, o que / nos separa? Que diferença há / entre mim e a serpente das palmeiras?" Já no Catorze: "Movidos pelo fogo/cada um ia sendo o centro de outro."

Essa imagética corresponde à importância do desejo para os poetas de Cartucho, que bem pode ser designada como poética do corpo. Em Joaquim Manuel, apresenta-se de maneira exemplar: "É assim, eu sei. Depois de se querer tudo/ queremos só corpo e depois nem isso"; "De olhos esquecidos sigo-me / o corpo, sigo-lhe o corpo"; "Que vou fazer do corpo tão distante", "As ligações entre a razão do mundo e a razão do corpo / são passageiras.” Tanto o corpo como suas partes, metonimicamente poetizadas, se repetem em rostos, bocas, mãos, olhos, circunscrevendo o objeto do desejo. É um desejo maldito; realizado em ambientes promíscuos, uma vez que não é socialmente permitido, o que comentaremos mais adiante.

Importante também seria delinear aqui o processo de efeminação do sujeito apaixonado. Para Barthes, “... todo homem que fala a ausência do outro, feminino se declara: esse homem que espera e sofre, está milagrosamente feminizado. Um homem não é feminizado por ser invertido sexualmente, mas por estar apaixo- 
nado." 9 Já Levinas nos fala sobre a volúpia como transfiguradora do sujeito; o qual passa a ter sua identidade definida não graças à sua iniciativa de poder, mas à passividade do amor recebido: “...a perturbação do sujeito [na volúpia] não se assume como um domínio do sujeito, mas é o seu enternecimento, a sua efeminação..." ${ }^{10}$ Tais características equivalem às do sujeito do discurso de Antônio Palolo, como em:

E eu que só queria tocar-te os olhos, os ombros tapados pela camisola, junto do rio, cobrir-me de chuva longe das ruas do meu bairro no prazer perdido, na memória finda.

Ou:

Uma vez só que seja deixa-me eu tocar-te de novo, eu escondo a cara, eu não digo nada (...) apenas devagarinho uma história para tu dormires, eu já vou tomar contigo uma bica, uma cerveja, o que tu quiseres.

Até aqui comentamos aspectos da poética de Joaquim Manuel Magalhães como um todo; apontando algumas correspondências com a teoria psicanalítica freudiana. Passamos agora à análise do homoerotismo em relação à nossa cultura e aos preconceitos decorrentes, tendo como base os estudos de outro psicanalista, nosso contemporâneo: Jurandir Freire Costa; uma vez que tais questões perpassam, ainda que sutilmente, os textos aqui estudados.

Nesse ponto não podemos deixar de mencionar os conceitos de Freud sobre a homossexualidade. Para ele, trata-se de um distúrbio sexual, do mesmo nível da perversão. Os homossexuais seriam os invertidos, "nos quais, de maneira ainda não compreendida, o objetivo sexual foi defletido do sexo oposto." 11

\footnotetext{
${ }^{9}$ BARTHES, 1981. p.28.

${ }^{10}$ LEVINAS, 1988. p.249-252.

${ }^{11}$ FREUD, 1987. p.195.
} 
Jurandir Freire Costa rebate veementemente esse conceito: ...a idéia da estrutura homossexual como uma modalidade de estrutura perversa é uma idéia filha de Kraft-Ebing e de alguns momentos infelizes de Freud que, em certos estudos deixou-se contagiar pelo vírus do preconceito psiquiátrico do século XIX. ${ }^{12}$

Considera inconsistente tal tese, uma vez que os sintomas do pervertido encontram-se em neuróticos e psicóticos, homossexuais ou não; centraliza a questão do homoerotismo no desejo, e, conceitua as meras classificações de homossexuais e heterossexuais de inúteis e preconceituosas. Daí preferir o termo "homoerotismo", o qual, aliás, é utilizado no presente estudo. Trata-se então de se pensar e de se aceitar a nova forma de desejo que o homoerotismo apresenta. Muito acertadamente lembra que o erotismo não obedece à codificação moral, seja da ciência ou da sociedade como um todo. E analisa a literatura como definidora do perfil do homossexualismo masculino, nos maiores autores da literatura universal: Proust, Gide, Balzac, Faulkner, dentre outros.

Em A inocência e o vício o autor dedica dois capítulos especialmente ao homossexualismo nas obras de Gide e de Proust. Neste, o homoerotismo como vício descreve o homossexual como invertido, anormal, como praticante do amor anti-social; uma visão naturalista que subscreve os preconceitos burgueses de sua época, e, ao mesmo tempo, inocenta-o de sua própria sexualidade: "Na ciência, pensava Proust, estava o aval da inocência. Estava a verdade que permitia redimir o homoerotismo, sem devolver sua sexualidade à sarjeta ou ao crime." ${ }^{13}$ Numa analogia, diríamos que o homoerotismo de Joaquim Manuel Magalhães aproxima-se do de André Gide, para o qual nunca explicitar o sexo do parceiro ou nunca dizer "eu" é mentir. No poeta português, o que temos é o exercício revolucionário de tirar a máscara e desmistificar a dignidade da pessoa do autor, um homossexual assumido.

\footnotetext{
${ }^{12}$ COSTA, 1992. p.85.

${ }^{13}$ COSTA, 1992. p.113.
} 
A leitura de Jurandir Freire Costa aponta também para o espaço designado socialmente ao homossexual: o gueto. É um circuito de locais de encontros exclusivos de homossexuais, que vão de praias a pontos de prostituição masculina:

Nesses locais, alguns extremamente sórdidos, os indivíduos gozam da liberdade que a discriminação permite. Mas justamente por tratarse de uma liberdade vigiada e concedida, carrega todas as sequelas do preconceito (...) se sentem promíscuos e convivendo com a promiscuidade, realizando assim, a imagem do homossexual criada pelo estereótipo do preconceito. ${ }^{14}$

Tais descrições estão em conformidade com os espaços referidos nos poemas de Antônio Palolo; bem como a angústia e o sentimento de culpa que resultam da discriminação:

Um riso triste pega no isqueiro.

Entra-se na praça por escadas de cimento e lixo entornado pelos cães.

Acende-o. Queima.

corpo na boca doutro corpo.

Por pequenas horas, por alguns escudos.

Vou-me embora. Vou sem ti. Este recanto

foi o último, parece uma ruína (...)

Noutro: "Vais cada vez mais cedo para a rua/dantes só o outro dia te levava. / Não tem mal, deixa-me falar / das pessoas encontradas num jardim". E no poema Cinco: "As ruas não te levam a ninguém."

Interessante as observações feitas em $A$ inocência e o vicio sobre o que domina no espaço do gueto homoerótico: a mínima fala, a inflação de gestos, sinais e atos, de modo a indicar com precisão onde está o desejo; a relação sexual sem metáforas, o anonimato, a parcialização do contato, a otimização e maximização do prazer, no curto espaço e no pouco tempo que a vida clandestina permite. Toda essa realidade nos é revelada nos poemas de Antônio Palolo.

${ }^{14}$ COSTA, 1992. p.96. 
No gueto, criação clandestina enquanto resposta do homoerotismo ao social, a única lei é a do desejo e da transgressão; e o clima de permissividade não só escandaliza o preconceito mas acaba por realmente mostrar o homossexualismo pervertido. Tal espaço é exemplarmente representado no poema Oito já citado, o qual nos soa como um grito de desespero: "No bolso furado os dedos masturbamme. / E que queres? Que te foda de pé? Que me vá / embora?"

Há ainda no estudo de Jurandir F. Costa a referência à dissimetria social, ou seja, a procura dos homossexuais por parceiros de classes inferiores; a tese do homossexual como "trânsfuga" de classe. Essa característica identificada nas obras de Gide e de Proust, encontra-se nos textos do nosso poeta português, como no poema Três, que, conforme já vimos, descreve uma transa com um empregado de supermercado: “... com o pó das horas de trabalho (...) entre dentes rasgados pelas cáries / mas sorrindo tanto sob a pele escura.” A conotação marginal da descrição é reforçada por "erva", sugerindo maconha.

Nesse trabalho, tentamos nos aproximar de aspectos fundamentais da poética de Joaquim Manuel Magalhães, sem, evidentemente, esgotar as possibilidades de análise que a riqueza de seu texto oferece. Seria interessante, por exemplo, numa perspectiva formal, estudar a excentricidade léxica, o uso de arcaísmo, as associações inesperadas, a sonoridade, o desempenho prosódico.

$\mathrm{Na}$ necessidade de delimitar um aspecto, optamos pela temática homoerótica, evidente no texto do poeta português, mas nem por isso irrelevante como matéria de estudo. O discurso homoerótico, registrado na literatura desde o famoso Banquete de Platão, é retomado nessa poética de maneira tocante. São recuperados, dentre outros, motivos medievais da cantiga de amigo, o decadentismo do amor maldito, a efeminação do sujeito apaixonado; a nosso ver, muito do neo-romantismo, travestido no amor homoerótico; e, principalmente, a "ética" gideana, no sentido de tirar a máscara e desmistificar o próprio homoerotismo, a despeito de toda a dor, de toda a culpa e de todo preconceito. 
Indagamos se não seria importante analisar até que ponto ou de que forma o "impeto de se contar" se faz no poeta "por máscara ou directamente", e que seria matéria para outro estudo.

\section{Referências Bibliográficas}

AA. VV. A phala. Um século de poesia. Lisboa: Assírio \& Alvim, 1989. AMARAL, Fernando Pinto do. O mosaico fluído. Lisboa: Assírio \& Alvim, 1991.

BARTHES, Roland. Fragmentos de um discurso amoroso. Rio de Janeiro: Francisco Alves, 1981.

BASTOS, Jorge H. Vias e desvios. Cult/Dossiê, São Paulo, n.27, p.5255, out. 1999.

COELHO, Eduardo Prado. A noite do mundo. Lisboa: Imprensa Nacional - Casa da Moeda, 1998.

COSTA, Jurandir Freire. A inocência e vício. Rio de Janeiro: RelumeDumará, 1992.

FREUD, Sigmund. Edição Standard Brasileira das Obras Psicológicas Completas de Sigmund Freud. Rio de Janeiro: Imago, 1987.

LEVINAS, Emmanuel. Totalidade e infinito. Lisboa: Edições 70, 1980. MAGALHÃES, Joaquim Manuel. Alguns livros reunidos. Lisboa: Contexto, 1987.

MAGALHÃES, Joaquim Manuel. Os dois crepúsculos. Lisboa: A Regra do Jogo, 1981.

PEREIRA, Edgard. Portugal: poetas do fim do milênio. Rio de Janeiro: Sette Letras, 1999.

PEREIRA, Edgard. A poesia portuguesa contemporânea. Estado de Minas/Pensar, Belo Horizonte, p.7, 24 abr. 1999.

PLATÃO. O banquete. São Paulo: Abril Cultural, 1983.

STAIGER, Emil. Conceito fundamentais da poética. Rio de Janeiro: Tempo Brasileiro, 1972. 


\section{Resumo}

Análise de aspectos básicos da poética de Joaquim Manuel Magalhães; em especial, da visibilidade homoerótica e dos efeitos dela decorrentes.

\section{Abstract}

An analysis of basic aspects of the poetics of Joaquim Manuel Magalhães; especially regarding homoerotic visibility and the effects which result from it. 